ISSN: 0514-7336

DOI: http://dx.doi.org/10.14201/zephyrus2016775978

\title{
PLANTEAMIENTOS INTERPRETATIVOS PARA EL ARTE LEVANTINO A PARTIR DEL ESTUDIO DEL ABRIGO DEL ARQUERO DE LOS CALLEJONES CERRADOS (ALBARRACÍN, TERUEL)
}

\section{Interpretative approaches for the Levantine rock art according to the study of Arquero de los Callejones Cerrados shelter (Albarracín, Teruel)}

\author{
Manuel BeA* y Jorge Angás Pajas** \\ * Grupo PPVE. Dpto. de Ciencias de la Antigüedad. Facultad de Filosofía y Letras. Cl Pedro Cerbuna, 12. 50009 \\ Zaragoza. Correo-e: manubea@unizar.es \\ ** Scanner Patrimonio e Industria. Avda. Navarra, 103 (local). 50017 Zaragoza. Correo-e: j.angas@3dscanner.e
}

Recepción: 2/09/2015; Revisión: 6/02/2016; Aceptación: 20/03/2016

\begin{abstract}
Resumen: Se presenta el estudio del abrigo del Arquero de los Callejones Cerrados, en la Sierra de Albarracín. En su documentación se han combinado diversas técnicas fotográficas y geométricas, tratamiento digital de las imágenes y confección de calcos digitales. A partir del análisis de los paneles pintados de tendencia naturalista, en color rojo y blanco, se ha documentado la existencia de una panoplia muy completa de especies animales que, además, aparecen conformando escenas con evidente carga simbólica junto a figuraciones humanas. El objetivo original consistía en establecer un mejor conocimiento del arte levantino a escala regional. El análisis realizado nos ha permitido observar una estrecha relación entre figuras femeninas y una posible escena de apareamiento de bóvidos que invita a realizar apreciaciones teórico-interpretativas novedosas. Éstas se orientan tanto a la existencia efectiva de una posible domesticación animal como a la posibilidad de subrayar el valor simbólico de una escena de fertilidad con implicaciones cronoculturales alejadas de las tradicionalmente apuntadas para el denominado arte levantino. En esta línea, se plantea la necesidad de abordar una redefinición general para el propio concepto de arte levantino.

Palabras clave: Sierra de Albarracín; estilo; pigmento blanco; escena ritual; domesticación; fecundidad; calcos digitales.

Aвstract: The study on the rock art shelter of Arquero de los Callejones Cerrados, in the mountain range of Albarracín, is presented. We combined different methods on its documentation, attending to photography, geometric techniques, image digital enhancement and digital tracings. According to the analysis of the naturalistic decorated panels, depicted in red and white colour, it has been documented a wide group of animal species, some of them forming symbolic scenes together with human figures. The main focus of the study was to establish a better knowledge of the rock art on a regional scale. The analysis carried out allows us to point out a close relationship between female motifs and a feasible mating scene between two bovines, which invite to make new theoretical and interpretative evaluations. So it is possible to note a scene with already tamed animals and also to highlight the symbolic value of a fertility scene, with all those chrono-cultural implications it has out of those traditionally used for the so-called Levantine rock art. In this hand, we also set out the necessity to address a general redefinition of the Levantine rock art concept.
\end{abstract}

Key words: Mountain range of Albarracín; style; white pigment; ritual scene; taming; fertility; digital tracing. 


\section{Introducción}

El abrigo del Arquero de los Callejones Cerrados (Albarracín) se localiza en el núcleo norte de los tres definidos en la Sierra de Albarracín, en las cercanías de la zona denominada "El Arrastradero",
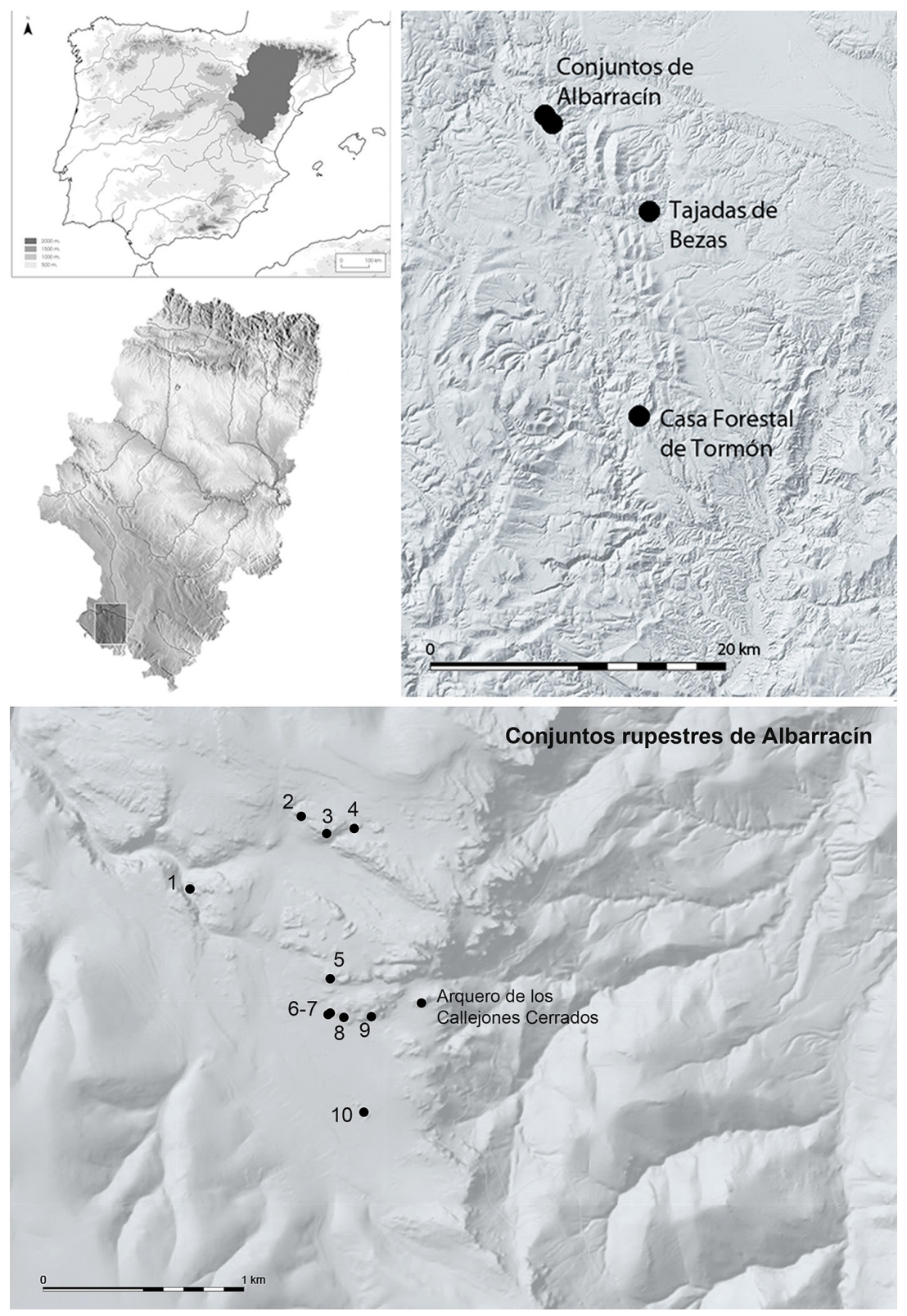

Fig. 1. Localización del abrigo del Arquero de los Callejones Cerrados: 1) Fuente del Cabrerizo; 2) Abrigo de Lázaro; 3) Prado del Navazo; 4) Tío Campano; 5) Cocinilla del Obispo; 6) figuras diversas; 7) Abrigo del Ciervo; 8) Medio Caballo; 9) Dos Caballos; 10) Doña Clotilde. donde se agrupan los conjuntos rupestres de Figuras Diversas, Abrigo del Ciervo, Medio Caballo y Dos Caballos (Fig. 1).

Fue descubierto oficialmente por M. Almagro, tras la notificación de su existencia por parte de un trabajador de la explotación de una cantera de la zona, dándolo a conocer en 1952 en el II Congreso $\mathrm{Na}$ cional de Arqueología (Almagro, 1953). Tras este primer estudio, las referencias al conjunto resultan relativamente escasas y circunscritas esencialmente a la publicación previa más que a una revisión efectiva del conjunto (Beltrán, 1968). El estudio de las, por entonces, dos únicas representaciones contenidas en el abrigo sería retomado con posterioridad por F. Piñón, quien proporciona una descripción completa de las mismas y realiza el calco de la segunda de las figuraciones que, hasta ese momento, había sido referida pero nunca publicada (Piñón, 1982: 100-104).

A principios de la década de los 90 del s. xx, se acomete una revisión pormenorizada de muchos de los conjuntos rupestres conocidos de Albarracín. El abrigo que nos ocupa es uno de los más destacados dentro de ese proceso de reestudio, refiriéndose al mismo como "el más sorprendente de todo el conjunto de Albarracín” (Herrero et al., 1994: 27), ya que se descubre un nuevo panel que, hasta el momento, había pasado absolutamente desapercibido. Sin duda, el color blanco muy desvaído de las figuraciones hace que éstas resulten prácticamente 
imperceptibles a la luz del día. Sin embargo, a pesar de la importancia del descubrimiento, fue dado a conocer de forma muy sintética, con una descripción absolutamente breve y con un aparato gráfico de muy reducidas dimensiones y escaso detalle (Collado, 1990, 1992a y 1992b; Herrero et al., 1994; Nieto $e t$ al., 1994), lo que ha propiciado que en estudios posteriores su existencia apenas si se haya reseñado (Beltrán, 1993: 154; Martínez, 2012) ${ }^{1}$ o ni siquiera recogido (Beltrán, 2002; Utrilla, 2000, 2005).

Así, a pesar de la importancia meridiana del conjunto, su conocimiento ha pasado prácticamente desapercibido para los estudiosos del arte rupestre. Esta circunstancia determinó que nos planteáramos como uno de los objetivos del proyecto, junto al de su documentación exhaustiva, el de dar a conocer los contenidos temáticos y estilísticos de un conjunto de gran interés regional.

En 2014 llevamos a cabo una revisión global del abrigo en la que se ha contemplado la documentación integral del mismo ${ }^{2}$ con la confección de calcos digitales, escaneado tridimensional y fotogrametría. La documentación del abrigo, especialmente la relativa al panel 3 -con figuraciones blancas desvaídas-, se hizo de noche, con iluminación artificial, mediante lámparas led de luz blanca de 800 lx de iluminancia, $5600{ }^{\circ} \mathrm{K}$ de temperatura y uso de difusor neutro, lo que aportó homogeneidad lumínica en todas las tomas fotográficas, para las que también se usó carta de calibración colorimátrica para la corrección del color en el postprocesado de las fotografías. Esta documentación, así como el posterior tratamiento digital de las imágenes mediante $D$-Stretch@, nos ha permitido la confección de nuevos y minuciosos calcos digitales de los paneles decorados.

1 Cf. también Calvo, M. J. (1993): El Arte Rupestre Postpaleolitico en Aragón. Tesis doctoral inédita defendida en 1993 en la Univ. de Zaragoza, pp. 443-445.

2 El proyecto de estudio integral de los abrigos rupestres de Albarracín (fase I) ha sido financiado a través de la Dirección General de Bellas Artes y Bienes Culturales del Ministerio de Educación, Cultura y Deporte, y se inserta dentro del proyecto "Transiciones climáticas y adaptaciones sociales en la Prehistoria de la cuenca del Ebro" (HAR201459042-P) así como en el Grupo "Primeros Pobladores del Valle del Ebro" (H-07).
Tras la elaboración de los nuevos calcos digitales y de la descripción de las unidades gráficas se pudo realizar una novedosa lectura escenográfica que, en conjunto con aspectos temáticos y estilísticos, ha determinado la necesidad de abordar cuestiones de carácter terminológico y de definición del arte rupestre de tendencia naturalista postpaleolítico, al menos desde una perspectiva regional.

El estudio integral de este abrigo se enmarca en un amplio proyecto de revisión global de los conjuntos rupestres de la sierra de Albarracín. Así, pretende ahondar en un mejor conocimiento del arte rupestre postpaleolítico de este territorio y analizar, mediante afinidades y disparidades, posibles conexiones temático-estilísticas y cronoculturales con territorios limítrofes, tratando de vislumbrar la compleja realidad del panorama artístico postpaleolítico peninsular.

\section{Descripción de los motivos}

El conjunto se localiza en una formación de rodeno rojo, propia de las afloraciones de arenisca del Triásico inferior, conformada por gravas, gravillas y arenas (Aurell et al., 2010) que surgen a partir de la erosión del macizo paleozoico ibérico. El abrigo se abre hacia el s, dominando una zona más baja de bosque de pino y prado, y casi en el extremo de una formación torriforme que se destaca en el entorno. Sus dimensiones resultan notables, atendiendo a la norma de los conjuntos rupestres de la zona, contando con $9 \mathrm{~m}$ de longitud, $4 \mathrm{~m}$ de profundidad $\mathrm{y}$ 5,3 $\mathrm{m}$ de altura máxima. El abrigo adopta una característica morfología cuadrangular, con la pared oriental cerrando en parte el conjunto al disponerse en ángulo con el friso que alberga los paneles decorados. Una gran fisura vertical divide el abrigo en dos partes bien diferenciadas, a la izquierda se localiza el panel 1 y a la derecha los paneles 2 y 3 (Fig. 2).

\subsection{Panel I}

Motivo 1. Dos trazos lineales verticales de color rojo oscuro que formaron parte de un único elemento, pero del que se ha perdido la zona medial 


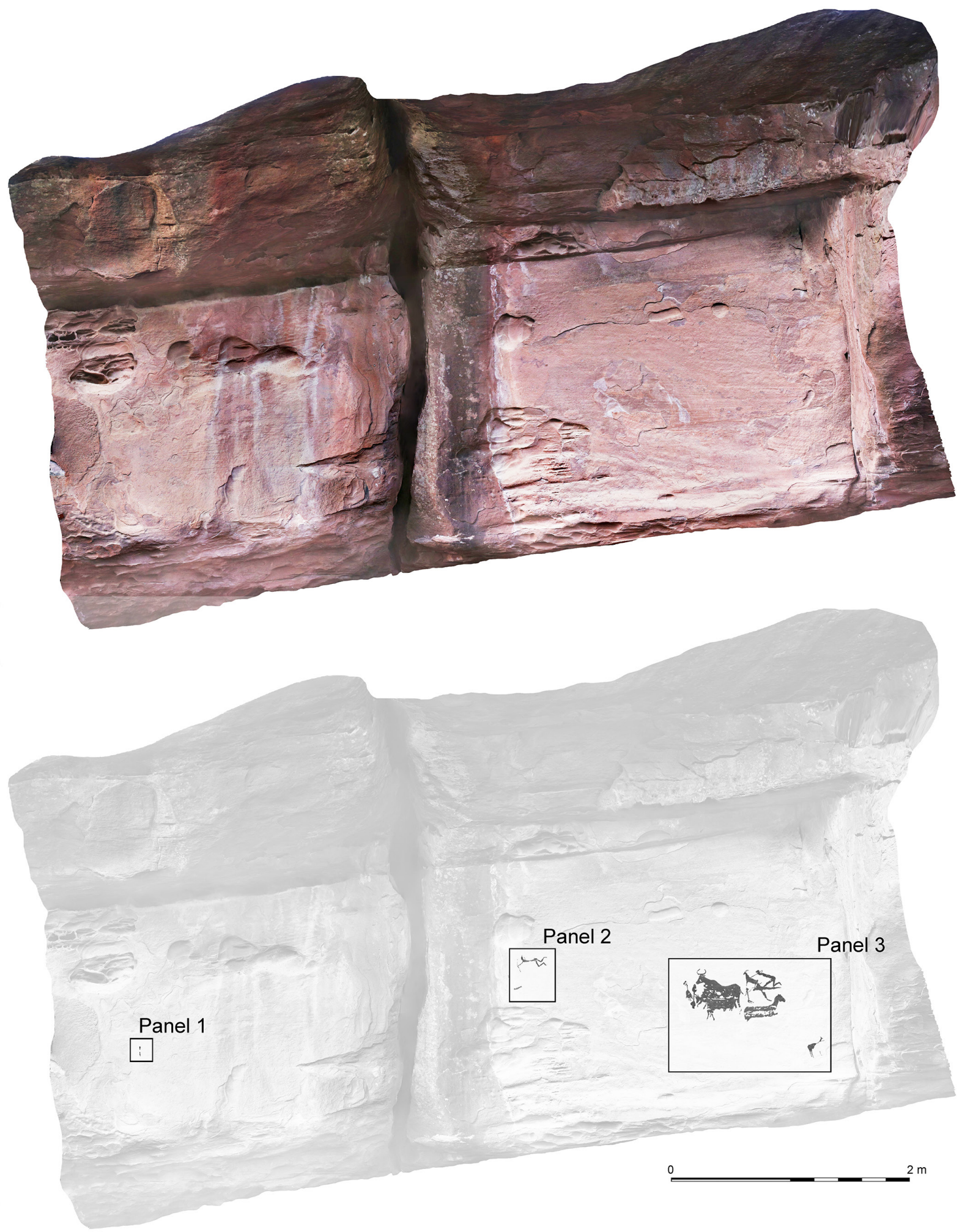

Fig. 2. Distribución de los paneles decorados del Arquero de los Callejones Cerrados. 
(Fig. 3). El primero mide 3,2 $\mathrm{cm}$ de longitud y 0,9 $\mathrm{cm}$ de grosor máximo, mientras que el inferior alcanza los 3,4 cm de longitud.

Resulta imposible identificar este elemento como una representación humana, independientemente del grado de esquematismo con el que se quiera definir (Piñón, 1982: 102-103), si bien se ha descrito como un antropomorfo filiforme mal conservado para el que se llegan a aludir dos ligeros trazos en la cabeza a modo de 'orejitas' (Piñón, 1982: 103).
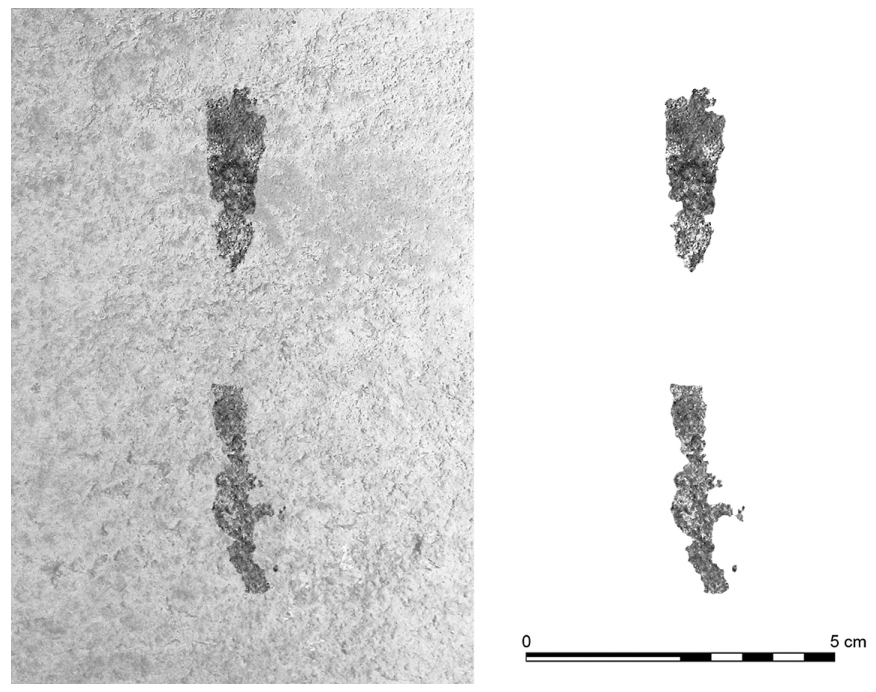

FIG. 3. Motivo 1 (panel 1), trazo vertical.Callejones Cerrados.

\subsection{Panel 2}

Motivo 2. Arquero de color rojo dispuesto a la izquierda. Es una de las figuraciones más representativas del arte rupestre de la sierra de Albarracín -siendo el logotipo identificador del Parque Cultural- y de la que se ha señalado su inusitada disposición, tendida en el suelo "... de la que no conocemos otro ejemplar en el arte levantino...” (Beltrán, 1968: 141).

El motivo, de 24,2 cm de longitud máxima, se define como la representación estilizada de un arquero en una nada habitual posición horizontal con las piernas separadas y flexionadas, en una de las cuales se ha plasmado perfectamente la pantorrilla
(Fig. 4, n. ${ }^{2}$ ). La representación de los pies se aprecia con claridad, alcanzando ambos unas grandes dimensiones. El pie inferior descansa apoyado en un pequeño canto rodado que sobresale de la roca natural en lo que, sin duda, aparece como un aprovechamiento natural del soporte.

Prácticamente en la unión de las piernas y el cuerpo se aprecia un trazo lineal hacia abajo que se ha interpretado tradicionalmente como el sexo (Almagro, 1952: 115; Piñón, 1982: 103; Beltrán, 1993: 154). Sin que se pueda, en absoluto, descartar esta interpretación, también se podría valorar su lectura como un elemento ornamental, tipo cinta, ya que tras el análisis digital de la fotografía se ha podido apreciar algún otro resto de color en la zona superior de la figura, a la altura de la cadera. Esta misma observación se pudo realizar para el famoso arquero del abrigo del Prado de las Olivanas que marcha hacia un cérvido moribundo. En este caso un trazo lineal curvado hacia abajo ha sido siempre definido como el sexo del individuo, a pesar de su anómala disposición en el abdomen. El tratamiento digital de la imagen ha permitido apreciar restos, muy mal conservados y muy poco visibles, de otro trazo similar en la zona posterior del arquero, lo que nos ha llevado a plantear su identificación como elementos de adorno, en la línea de lo observado en otros motivos, como los de la Tía Mona (Alacón, Teruel).

El cuerpo tiene tendencia lineal, aunque se ensancha progresivamente hacia los hombros. Los brazos fueron representados en disposición y actitud bien diferenciada. El derecho en la zona superior de la figura, apenas esbozado mediante un trazo lineal muy fino y mal conservado, aunque es posible apreciar la inflexión del codo. El brazo izquierdo se representó estirado hacia delante, ligeramente inclinado hacia abajo y sustentando un arco. La cabeza se muestra erguida, con una morfología ovalada y rematada por una especie de elemento de tendencia lineal o casi cónico.

Motivo 3. Restos de color blanco, probable representación de una pierna de antropomorfo (Fig. 4, n. ${ }^{\circ} 3 \mathrm{a}$ ). Trazo lineal en disposición horizontal 

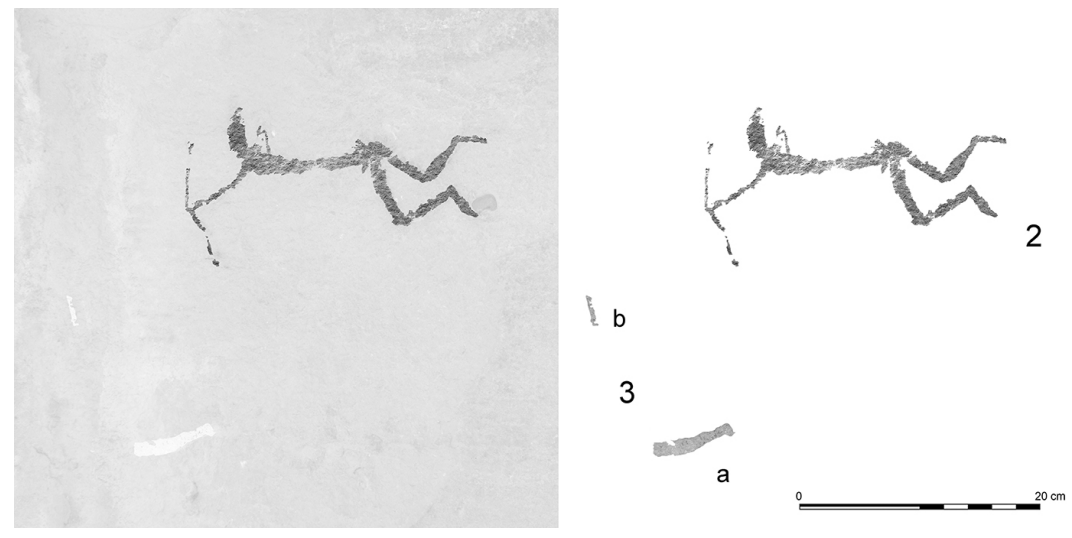

FIG. 4. Motivos del panel 2: arquero (2), restos de color blanco, posible pierna de antropomorfo (3a) y resto lineal de color blanco (3b).

\subsection{Panel 3}

Este panel (Fig. 5) fue descubierto durante unos trabajos de revisión de los abrigos rupestres de Albarracín en 1991, aunque no se pudo proceder a la documentación del mismo hasta un año después (Herrero et al., 1994). De ese estudio aparece publicada una muy escueta nota, sin apenas aparato descriptivo, en la que se da cuenta del descubrimiento de 10 nuevas figuraciones, todas ellas de color blanco (Nieto et al., 1994: 34). En trabajos posterio-

ligeramente curvo y en cuyo extremo derecho es posible observar el arranque de lo que podría interpretarse como un pie. Este motivo recuerda en disposición, aspecto formal y dimensiones a la pierna inferior del motivo 2 . A unos $10 \mathrm{~cm}$ por encima y algo desplazado a la izquierda, se observa un corto trazo lineal vertical (Fig. 4, n. ${ }^{\circ} 3 \mathrm{~b}$ ), también de coloración blanca y de 2,6 cm de longitud.

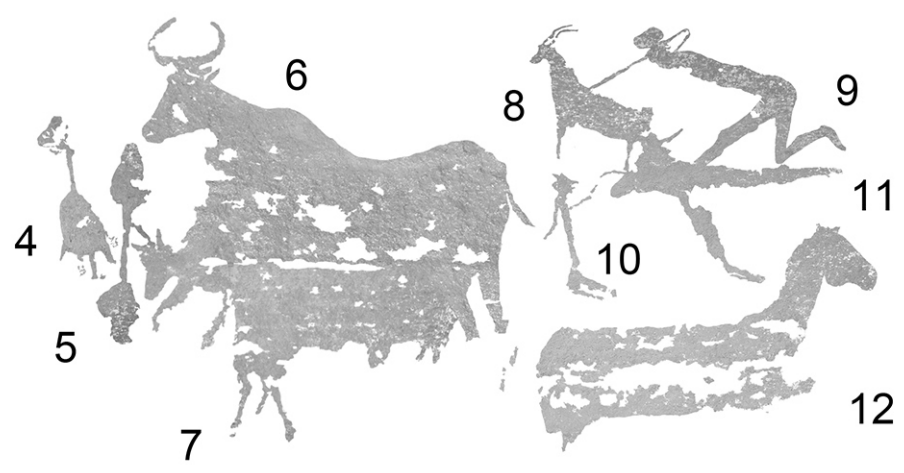

0

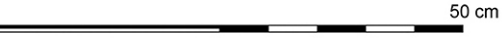

res, el panel referido no es objeto de una publicación minuciosa y sólo en una de ellas encontramos una referencia igualmente breve y un calco general de conjunto (Collado, 1992: 14-15), recogiéndose en otros trabajos simplemente la noticia del descubrimiento (Beltrán, 1993: 154), sin que en ningún momento se le diera la importancia que merece.

Motivo 4. Representación antropomorfa femenina orientada a la derecha. Se trata de una figuración antropomorfa estática, con una voluminosa cabeza, mal conservada, seguida de un cuerpo lineal vertical y larga falda con remate de dos picos a ambos lados que deja entrever por debajo parte de las pantorrillas.

Motivo 5. Representación antropomorfa femenina orientada a la derecha. Guarda relación evidente con el motivo anterior, formando escena con la misma. La actitud es idéntica: disposición vertical y

Fig. 5. Calco general del panel 3 del Arquero de los Callejones Cerrados. 
estática. La cabeza se conserva mejor que en el caso anterior, apreciándose su volumen, ya se trate de un tocado, de un peinado o de un complemento de la vestimenta -velo-.

En este caso, la representación de la falda sería más corta, de forma triangular y sin los acabados en pico de la anterior, aunque se aprecian mejor las piernas, que fueron representadas muy juntas y con indicación de los pies, que fueron representados juntos. La figura se presenta en estrecha relación con los motivos 6 y 7. A este último parece tocarle la cabeza con el único brazo que conserva.

Motivo 6. Gran bóvido orientado a la izquierda. Es la figuración de mayores dimensiones de todo el abrigo, alcanzando los $41,7 \mathrm{~cm}$ de longitud máxima. El grado de naturalismo en su ejecución resulta muy destacable, así como la fina ejecución técnica apreciable en la limpieza del trazo. La zona inferior del motivo resulta difícil de discriminar debido a la superposición existente entre este motivo y el n. ${ }^{\circ} 7$, así como a un mayor grado de deterioro en la zona.

Con todo, es posible definir bien los cuartos traseros, poderosos y redondeados, parte de las patas traseras y de la cola. El cuerpo, en su zona superior, se desarrolla con una destacada curva cérvico-dorsal que se enfatiza con una voluminosa joroba. El cuello del animal, alzado, presenta unas proporciones correctas al igual que la cabeza, con un gran detallismo y gusto naturalista, pudiéndose apreciar perfectamente sus diferentes partes: quijada, morro, testuz -ligeramente cóncava-, una protuberancia señalando la ceja así como las orejas, representadas de forma convencional, las dos en la parte trasera de la cabeza, de forma alargada y paralelas entre sí. Los cuernos se representaron en la parte más alta, de grandes dimensiones y con forma de media luna. Como ya se ha apuntado, la parte inferior del motivo resulta muy confusa, aunque consideramos que los dos trazos lineales que sobrepasan el cuello del motivo 7 podrían interpretarse como las patas delanteras del que nos ocupa.

Las diferencias morfológicas y de dimensiones de este motivo con respecto al 7, así como la plasmación de determinados rasgos sexuales bien subrayados -como la poderosa cornamenta, el volumen de la joroba y línea dorsal bien modelada-, podrían explicarse a partir de un marcado dimorfismo sexual, cuestión ya considerada por $\mathrm{Rubio}^{3}$ para otros conjuntos rupestres y que se ha apuntado como una “... línea interesante de interpretación...” (Domingo et al., 2003: 33).

Motivo 7. Gran bóvido orientado a la izquierda. Aunque cuenta con unas dimensiones apreciables $-33,7 \mathrm{~cm}$ de longitud máxima-, sus rasgos identificativos como bóvido están más suavizados que en el motivo 6: menor grosor del cuerpo, patas más finas, cabeza y cornamenta más pequeña, todo lo cual nos hace proponer su interpretación como posible hembra.

El motivo presentaría una marcada desproporción en la longitud del cuello, demasiado largo y fino respecto del cuerpo. Esta característica se podría explicar como un recurso del artista para encajar las patas delanteras del motivo 6 precisamente sobre la zona delantera del motivo 7 , con la finalidad de hacer más comprensible el significado de la escena.

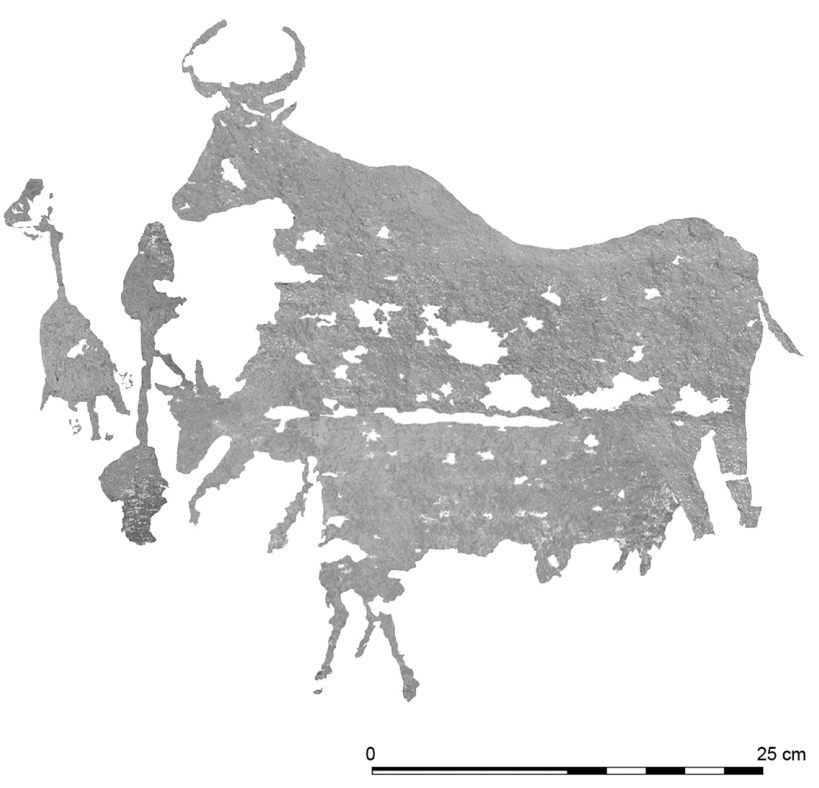

Fig. 6. Detalle de la escena compuesta por dos bóvidos (en posible escena de acoplamiento) y dos mujeres; una de ellas toca con la mano la cabeza de uno de los bóvidos.

${ }^{3}$ Rubio, M. (1993): Arte Rupestre Levantino: figuras zoomorfas. Tesis doctoral inédita defendida en 1993 en la Univ. de Alicante, p. 835. 

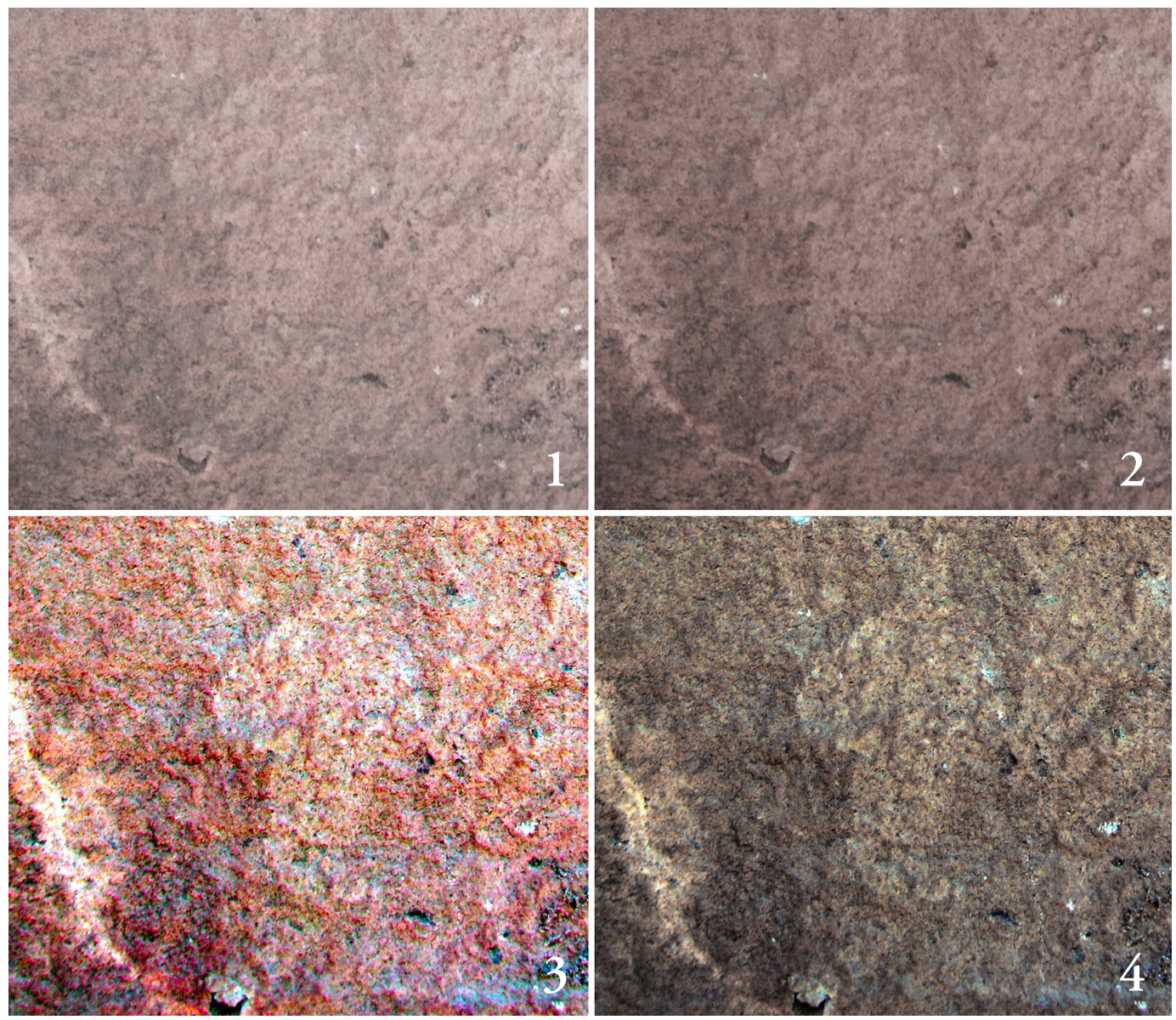

FIG. 7. Detalle de la representación de las piernas del motivo 5: 1) fotografia original; 2) fotografia con tratamiento digital; 3-4) fotografia con tratamiento mediante DStretch. La morfología atípica de extremidades se percibe claramente, sin que pérdidas del soporte o pigmento hayan condicionado su lectura.

En esta línea, consideramos que se podría ver una escena de acoplamiento o monta del toro -motivo 6- sobre una vaca -motivo 7-, en la que el macho se subiría sobre la hembra, apoyando sus extremidades delanteras sobre la vaca. Si el artista no hubiera recurrido a la exageración del cuello para plasmar la monta de las patas delanteras, la técnica empleada -tinta plana- no permitiría distinguir entre el acto referido o una mera superposición de motivos ${ }^{4}$.

${ }^{4}$ Resulta evidente que la escena no obedece exactamente a la disposición de monta tal cual sucede en la realidad, ya que el macho no suele apoyar sus extremidades delanteras más allá del desarrollo central del cuerpo de la hembra. Así, y si bien cabría también apuntar la posibilidad de un muy marcado dimorfismo sexual que explicara la disposición de ambos motivos,
Los rasgos suavizados de este zoomorfo -cara pequeña, morfología ligeramente apuntada del morro,

consideramos que el aspecto forzado de la monta representada se debe a la técnica empleada en su realización. Si se dispusiera a los sujetos de la escena en la posición normal sería en todo punto imposible realizar la lectura de la escena en los términos que se exponen, de manera que para el observador podrían no pasar de ser, simplemente, dos figuras superpuestas. La necesidad de hacer comprensible la escena y la dificultad de realización impuesta al artista por la técnica empleada determinarían la disposición convencional apuntada en el texto. En esta línea, se debe subrayar que dicha postura o disposición no resultaría más forzada, por ejemplo, que la empleada para representar a un arquero levantino al uso: cabeza de perfil, hombros de frente, tronco de perfil... entendiéndose como meras convenciones formales que tratan de aportar el máximo posible de información visual empleando la tinta plana. 
pata y pezuña finas-, compatibles con otras especies animales -cierva-, abundan, sin embargo, en su consideración como género femenino en contraposición a los rasgos expuestos para el motivo 6, identificado como macho. En todo caso, aspectos estilísticos como los apuntados no resultan, en modo alguno, ajenos a lo observado en el arte rupestre de la región, encontrando bóvidos con morro apuntado en abrigos como los de Prado de las Olivanas, Prado del Navazo o Figuras Diversas. Para la representación de patas y pezuñas estilizadas y gráciles encontramos buenos ejemplos en los bóvidos de Figuras Diversas, Prado de las Olivanas, el motivo 2 de la Ceja de Piezarrodilla o algunos de los nuevos hallazgos de la zona de Tormón.

Bien es cierto que la estilización de cuellos se encuentra presente en diferentes especies animales de abrigos de la sierra de Albarracín, aunque no se puede entender como un rasgo definitorio del arte rupestre de este territorio. Un cuello absolutamente desproporcionado se documenta en uno de los bóvidos del Prado del Navazo. Otros esbeltos -ya no desproporcionados- los encontramos en dos cérvidos de los abrigos de Paridera de las Tajadas y Contiguo a la Paridera, así como en tres ejemplares de cabras en el abrigo de Cabras Blancas (Tormón).

En la sierra de Albarracín, los bóvidos suelen tener un cuello de proporciones correctas e incluso resulta común, hasta cierto punto, encontrar bóvidos con los cuellos absolutamente cortos -Cocinilla del Obispo, Prado del Navazo, Prado de las Olivanas, Medio Caballo, Hoya de Navarejos III-. Así pues, consideramos factible interpretar la marcada desproporción del cuello como un recurso técnico configurativo para facilitar al observador la lectura de la escena. Aspectos como los reseńados, unidos al grosor y longitud del cuerpo del motivo 7, incompatibles con rasgos morfológicos de otras especies animales, han determinado su definición como bóvido.

Motivo 8. Cáprido orientado a la izquierda. El motivo zoomorfo se representó de forma muy naturalista y con proporciones elegantes, en actitud estática casi rígida, con las patas rectas y verticales. El cuello se plasmó muy erguido, al igual que la cabeza, como en estado de alerta. Dos finos, largos y curvos cuernos, en perspectiva de perfil, se representaron en la parte alta de la cabeza. La parte inferior trasera del animal resulta difícil de concretar al confundirse sus trazos con los del motivo 11.

El cáprido aparecería superpuesto al motivo 10, con el que, sin embargo, parece conformar una escena de carácter acumulativo en la que se habría pretendido dar la idea de que el humano atrapa al animal por la intersección entre el cuello y el cuerpo de éste.

Motivo 9. Antropomorfo orientado a la izquierda. Se trata de una representación humana de tendencia bastante naturalista y de dimensiones notables $-25,5 \mathrm{~cm}$ de longitud desde la cabeza al pie-.

Cuenta con unas buenas proporciones de todas las partes del cuerpo, aunque determinados elementos fueron representados de forma muy convencional y sin tratamiento específico o detallista -como los brazos-. El individuo presenta la pierna derecha flexionada, como apoyando la rodilla en el suelo, apreciándose bien el tratamiento muscular de la pantorrilla y continuando con la tendencia vista para el motivo 2 de representar el pie muy alargado. La pierna izquierda aparece extendida hacia delante, con una ligera inflexión a la altura de la rodilla bien definida.

Tras unas nalgas bien marcadas y redondeadas, el cuerpo aparece muy inclinado hacia delante, formando un ángulo de unos $45^{\circ}$ con la pierna izquierda. No se aprecian diferencias en el tratamiento del desarrollo del cuerpo, relativamente grueso con respecto a la norma general del arte levantino. La cabeza se plasmó como un elemento de forma ovalada.

Los brazos son los elementos del antropomorfo que menos dedicación presentan en su realización, habiendo sido realizados mediante meros trazos lineales muy finos. El derecho aparece por la parte trasera del cuerpo, alto y flexionado, en la misma disposición que el del motivo 2 de este abrigo o del 18 del Medio Caballo, como tensando un arco. El brazo de la izquierda aparece perfectamente extendido, recto y con una disposición ligeramente diagonal, nuevamente la misma posición que la apreciada para el arquero de color rojo del panel 2. 
La disposición del antropomorfo es la que nos invita a pensar en la posibilidad de que se tratase originalmente de la representación de un arquero y que, con posterioridad, se habría realizado la cabra, cubriendo el arco o aprovechando su morfología curva para la realización de la curva cérvico dorsal del motivo zoomorfo.

Motivo 10. Antropomorfo orientado a la derecha. Motivo humano estilizado parcialmente conservado $-13,2 \mathrm{~cm}$ de altura máxima-. Aparece sentado, con las piernas en paralelo y hacia delante, apreciándose sólo en la superior parte del arranque de la rodilla que indicaría una inflexión de la pantorrilla -no conservada- hacia abajo.

El cuerpo, de tendencia lineal, se representó vertical, ligeramente inclinado hacia atrás. Del extremo superior parten los brazos, sin más tratamiento que el definido como meros trazos lineales finos. El izquierdo parece desarrollarse hacia abajo, en paralelo al cuerpo, apreciándose una inflexión por el codo que dispondría el antebrazo hacia el exterior. El de

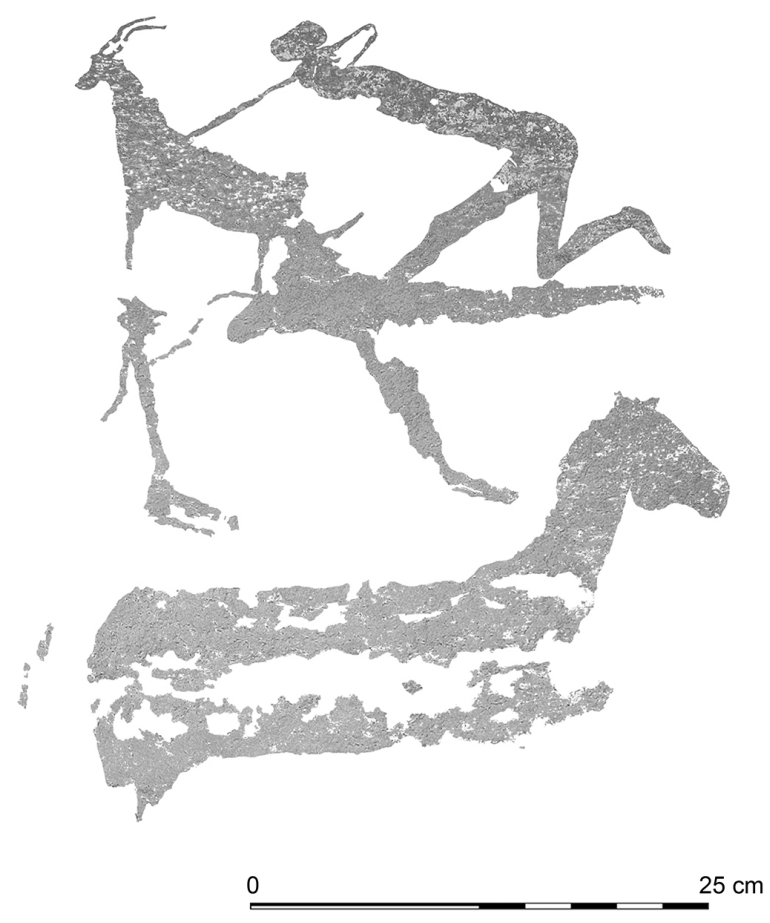

FIG. 8. Motivos de la zona derecha del panel 3. la derecha se representó en alto y algo flexionado, pudiéndose asir del extremo un elemento lineal curvo que llega a fusionarse con el motivo 11.

Motivo 11. Restos de un cuadrúpedo, posiblemente un bóvido. La indefinición del mismo viene determinada por el carácter inconcluso de la figura o por una conservación muy desigual. Se reconoce la cabeza, de tendencia triangular, en la que el hocico adopta una morfología curva y en la que aparece representada la quijada y un alto copete en el que se observa un corto cuerno que sale hacia la derecha. La parte izquierda de la cabeza se confunde con los cuartos traseros del motivo 8 .

Del corto cuello parte un trazo grueso hacia abajo, perfilando el pecho del animal, adoptando una forma curva que iniciaría el bajo vientre. En la zona superior se aprecia un trazo de iguales características pero horizontal y de desarrollo hacia la derecha que dibujaría el lomo del zoomorfo.

No llegamos a apreciar el desarrollo del vientre, muy abultado, ni el relleno interior del cuerpo que apuntara Collado (Collado, 1992: 15).

Motivo 12. Équido orientado a la derecha. Es una de las figuraciones más bellas de todos los conjuntos del Arrastradero e incluso de la sierra de Albarracín, de grandes dimensiones $(36 \mathrm{~cm}$ de longitud), elegantes proporciones, naturalista y preciso en su ejecución.

Se conserva el cuerpo, muy afectado por diversos desconchados, sobre todo, en la zona media a lo largo de todo su desarrollo horizontal. La grupa aparece potente y redondeada, y a escasos centímetros a la izquierda de ésta se aprecian unos restos lineales diagonales descendentes a la izquierda que interpretamos como los restos de la cola del animal. En el extremo inferior izquierdo se aprecia también el arranque de las patas traseras que, como las delanteras, se han perdido totalmente.

Tanto las líneas del vientre como del lomo aparecen bien ejecutadas, muy horizontales y paralelas entre sí.

El cuello fue representado erguido, muy fino, apreciándose en el recorrido superior una serie de suaves ondulaciones que aluden a la crin. Se aplicó 
un gran naturalismo en la plasmación de la cabeza, individualizando muy bien las diferentes partes de la misma, hasta el punto de que incluso llegan a ser convenciones algo exageradas, como en la curvatura del carrillo, quijada y labios. El frontal o testuz fue representado recto para dejar paso al copete, en el que se aprecian dos pequeñas orejas dispuestas en orientaciones opuestas.

Este motivo guarda estrecha relación estilística, proporciones y dimensiones con otros caballos representados en abrigos de la sierra de Albarracín, como el motivo 2 del Prado del Navazo o los motivos 7 y 10 del vecino conjunto del Medio Caballo.

Motivo 13. Restos de cuadrúpedo orientado a la derecha, posiblemente una cierva de $14,4 \mathrm{~cm}$ de longitud. Un gran desplacado ha afectado a casi la mitad delantera de esta delicada representación. Se conservan los cuartos traseros del animal, de perfecto naturalismo y elegantes proporciones, con unas patas finas y con detalles anatómicos -corvejón y

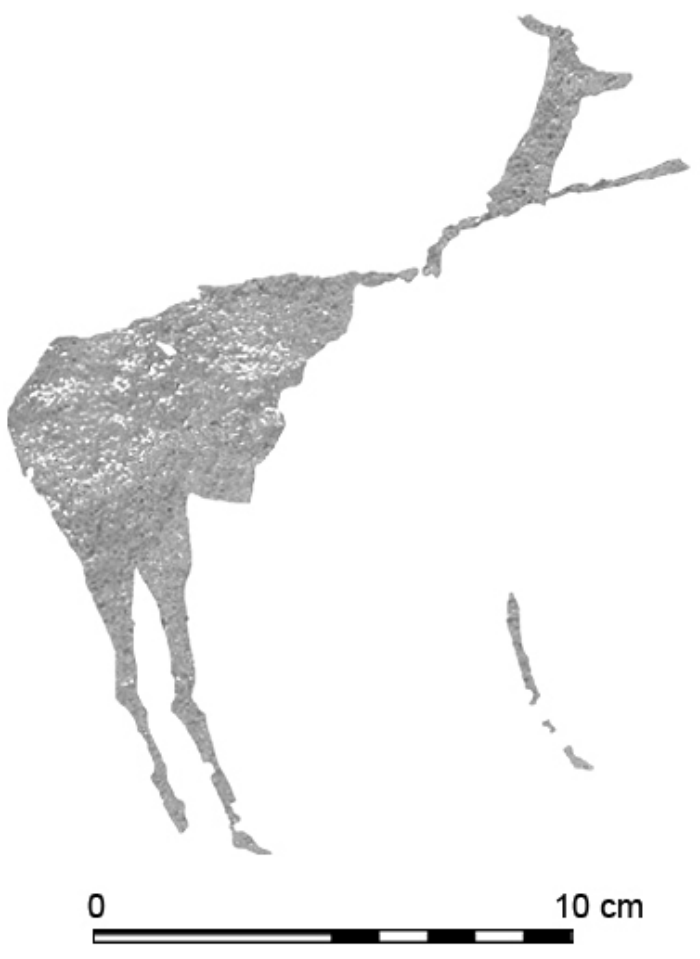

FIG. 9. Cérvido herido (motivo 13). el casco de perfil en la pata derecha-. Se aprecian también la ingle y el arranque del vientre, punto a partir del cual se pierde la figura.

En la parte superior todavía es posible reconocer casi todo el recorrido del lomo, ligeramente convexo, que da lugar a un fino, largo y enhiesto cuello. Sólo se conserva parte de la cabeza, con la mandíbula inferior y una pequeña oreja orientada hacia atrás. A pesar de la afección del desconchado, es posible observar restos pertenecientes a una de las patas delanteras, que presenta una disposición algo arqueada, lo que, junto a la postura global del cuerpo, subraya la posición ligeramente diagonal ascendente del animal. Destaca un trazo lineal fino perpendicular al cuello que se hunde en éste y que puede ser definido como un venablo o flecha.

\section{Estilo y composición}

El análisis de las representaciones que nos ocupan aportan interesantes aspectos estilísticos y temáticos para la definición global de los rasgos del arte de tendencia naturalista postpaleolítico regional, así como para tratar de establecer una base conceptual que sobrepase el aludido ámbito territorial.

En panel 3 del abrigo del Arquero de los Callejones Cerrados ofrece dos agrupaciones bien diferenciadas desde el punto de vista de la composición. La primera de éstas es la conformada por el grueso de motivos, en la parte superior, mientras que la segunda estaría compuesta exclusivamente por el motivo 13, físicamente separado de los anteriores. Asimismo, en la primera agrupación es posible observar hasta tres unidades diferenciadas, en función de la participación escénica y superposiciones. De este modo podemos aludir a una primera unidad compuesta por los motivos 4-5 -humanos- y 6-7 -bóvidos-; una segunda unidad -motivos 8-11-, en la que su integración vendría determinada por la existencia de superposiciones entre los diferentes motivos más que por la lectura de una escena diferenciada; y una tercera unidad, compuesta exclusivamente por el équido -motivo 12-, siendo el único animal orientado a la derecha. 
Un somero análisis estilístico subraya una evidente mayor diversificación morfológica en las representaciones humanas, siempre tendentes a la simplificación o estilización de sus formas. Con todo, dentro de ese esquema general tendente a la estilización, es posible observar formatos diferenciados en cuanto al tratamiento de determinados detalles anatómicos, volumen de las extremidades inferiores, proporción de los cuerpos y grado de simplificación de algunos elementos.

Así, contrasta el tratamiento otorgado al motivo 9 -tendente a la proporcionalidad de sus diferentes componentes anatómicos y con cierto detalle en el tratamiento volumétrico no exagerado de las piernas y correcta articulación de las extremidades- con el observado para las otras figuraciones, especialmente las de las mujeres -motivos 4-5-, temática que hasta el momento no se puede contrastar en ningún otro conjunto rupestre de tendencia naturalista de la sierra de Albarracín ${ }^{5}$, y que aparecen mucho más estilizadas, con un cuerpo carente de todo detalle, reducido a un mero trazo lineal y sin especificación de detalles anatómicos o de diferenciación externa más allá de la representación del atuendo -faldas- y una evidente desproporción volumétrica en el tercio superior o cabeza, quizá poniendo énfasis en algún tipo de peinado, tocado o velo.

El componente lineal en la conformación de los motivos antropomorfos estudiados resulta meridiano, atestiguándose perfectamente en el corpus rupestre de la sierra de Albarracín, en el que los tipos lineales, o incluso muy estilizados, son los más representados. Así, encontramos figuraciones con cierta preocupación por el tratamiento correcto de las proporciones y volumen anatómico en el mismo abrigo del Arquero de los Callejones Cerrados, en el panel 2, en el arquero de color rojo, pero también en el del Medio Caballo y Prado de las Olivanas. Son más numerosos, sin embargo, aquellos

5 En este punto hay que mencionar la interpretación, por parte de Beltrán (1997), del motivo 2 del abrigo de la Paridera de Tormón como una mujer a partir la figuración de pendientes. La documentación reciente llevada a cabo en el conjunto impide aseverar la anterior interpretación (Bea y Angás, 2015: 101).

(C) Universidad de Salamanca motivos más estilizados, sin apenas detalles ni gusto por la representación del volumen: Figuras Diversas, Prado del Navazo, Cabras Blancas, Hoya de Navarejos III.

Algo similar se desprende del escaso dinamismo plasmado en estas figuraciones, aspecto común en el contexto regional del abrigo. Con todo, debemos destacar que, si bien la carga dinámica de las figuraciones es escasa, los motivos humanos no se muestran absolutamente estáticos, desarrollando en casi todos los casos algún tipo de acción con los brazos.

En cuanto a las representaciones animales resulta evidente el alto grado de naturalismo en su representación, especialmente en el toro -motivo 6- y el caballo-motivo 12-. Este último, a pesar de que la mitad inferior no se ha conservado, presenta unas proporciones muy correctas, con especial cuidado por los detalles anatómicos mediante la plasmación elegante de la cabeza, con el belfo y la quijada bien delimitados y redondeados, plasmación de dos pequeñas orejas e incluso una suave ondulación en la zona superior del cuello para representar la crinera. El animal permanece en actitud estática, casi majestuosa, con el cuello alzado.

A pesar de que la del équido es una temática porcentualmente notable en la sierra de Albarracín, en comparación con la representación de esta especie en el global del arte levantino, lo cierto es que sus notables dimensiones y gran realismo hacen que encontremos solo dos paralelos cercanos en el vecino conjunto del Medio Caballo y en el de Prado de los Arejos I, resultando el resto de figuraciones de équidos de la sierra estilística y conceptualmente muy alejadas. Debemos destacar que en ninguno de los casos en los que se observa ese gran naturalismo en la representación de équidos existe asociación directa entre éstos y motivos antropomorfos, aunque compartan espacio.

Las figuraciones de cáprido y de cérvido -motivos 8 y 13- son las de menores dimensiones del conjunto, aunque siguen presentando rasgos naturalistas en su representación. Destaca el cérvido, en el que se combina una elegante y grácil composición de los cuartos traseros y detalles anatómicos destacados, como la plasmación de los corvejones. 
La esbeltez de la figura se aprecia igualmente en el desarrollo largo y elegante del cuello. Aspectos estilísticos como los apuntados se documentan bien en otros cérvidos de conjuntos de la serranía, como los de Paridera de las Tajadas, Contiguo a la Paridera en color blanco o en otros de mayores dimensiones y de color rojo, como los del Medio Caballo, Prado de las Olivanas o los de Prao Medias (Bea, 2014; Bea y Angás, 2015).

También para el cáprido se encuentran buenos paralelos estilística y técnicamente afines al que nos ocupa, coincidiendo igualmente en la coloración blanquecina empleada. Tal es el caso de las figuraciones del abrigo de Cabras Blancas y Casa Forestal de Tormón I y III.

Las representaciones de toros suponen uno de los temas más extendidos y representativos del arte levantino, caracterizándose, en general, por ser modelos de marcado naturalismo. Con todo, y tal y como se ha puesto de manifiesto en diversos estudios (Porcar, 1947; Beltrán, 1968; Rubio, 1995; Domingo et al., 2003) ${ }^{6}$, y de forma específica para la serranía de Albarracín (Piñón, 1982; Bea y Angás, 2015), es posible rastrear convencionalismos formales y técnicos que evidencian la existencia de variaciones regionales o cronológicas. Estos particularismos se documentan incluso en territorios que, de forma general, representan en sí mismos núcleos bien definidos, como los del Bajo Aragón-Maestrazgo turolense y castellonense o el de la sierra de Albarracín.

Así, las representaciones contenidas en el abrigo del Arquero de los Callejones Cerrados distan estilísticamente de las características más definitorias para los motivos de bóvidos del territorio circundante. Ya se han destacado las diferencias formales entre los bóvidos del panel 3, existentes incluso en motivos que forman parte de la misma escena, algo que, como se ha puesto de manifiesto con anterioridad, se explica por una diferenciación de rasgos sexuales. Con todo, los caracteres formales conservados del motivo 6, el más naturalista, contrastan abiertamente con los definitorios para el conjunto de bóvidos de la zona, aun cuando

$$
{ }^{6} \text { Cf. también Rubio, M., op. cit. n. } 3 .
$$

éstos se clasifican según parámetros igualmente tendentes al naturalismo.

La representación de toro, en aquellas partes bien conservadas, ofrece un alto grado de realismo en su definición, correctas proporciones y detalle en la plasmación de las orejas y morro del animal, con la frente cóncava perfectamente delimitada. Esta tendencia se documenta sólo para el tratamiento del motivo 7 de Cocinilla del Obispo, aunque incluso en este caso la cabeza es más corta y el patrón general del motivo mucho más desproporcionado. El naturalismo de la cara no parece haber sido una preocupación para el artista en el resto de figuraciones de bóvidos de la región. En estos casos las cabezas y caras de los animales se reducen a poco más que meras formas convencionales con morfologías que van de la tendencia triangular, a otras de desarrollo longitudinal con morro acabado en cuadrado o ligeramente redondeado, con muy escasas plasmaciones del detalle del morro o quijada.

La representación de una cruz destacada en el animal fue bien representada en otros ejemplares de la zona, especialmente en aquellos de mayores dimensiones en Cocinilla del Obispo y Prado del Navazo, remarcándose la línea dorsal también en motivos de Prado de las Olivanas, Medio Caballo y Ceja de Piezarrodilla.

Sin embargo, las dimensiones y proporciones corporales de los bóvidos del Arquero de los Callejones Cerrados se distancian notablemente de la generalidad observada en la sierra de Albarracín. Así, a pesar de contar con un notable tamaño -que lo llevaría a contabilizarse entre los bóvidos de mayores dimensiones de otras áreas geográficas como Bajo Aragón y Maestrazgo- (Fig. 11), tan sólo encontramos un único paralelo en cuanto a proporciones y tamańo en la zona, siendo el bóvido de color negro del Prado del Navazo. Todos los demás se distancian bien por aspectos estilísticos - Hoya de Navarejos $\mathrm{v}-$, de dimensiones aun teniendo proporciones correctas -Medio Caballo- o por el patrón longitudinal desproporcionado de su desarrollo corporal.

Otros rasgos anatómicos, como la representación en perspectiva torcida de los cuernos o la cola caída a lo largo de los cuartos traseros, concuerdan 
perfectamente con las características definitorias del arte rupestre circunscrito a ese territorio.

Variaciones formales, detalles y diversidad de tamaños subrayan la idea de que las manifestaciones de bóvidos presentan un amplio recorrido cronológico, sin que se puedan encuadrar de forma exclusiva en momentos antiguos (Domingo et al., 2003: 36; Cruz, 2004; Martínez Bea, 2008) ${ }^{7}$.

\subsection{Escenas}

Si bien en el conjunto se advierte la existencia de al menos un arquero y de un cérvido con una flecha clavada y, por tanto, se evidencia la práctica de actividades venatorias, lo cierto es que la definición de las escenas legibles en el panel 3, con participación directa de motivos humanos y animales, hace que se pueda plantear igualmente una posible representación de animales domésticos, al menos los bóvidos.

Hasta el momento, todas las escenas de posible domesticación definidas como levantinas tenían como protagonistas a figuraciones que no pueden, en modo alguno, ser descritas como plenamente naturalistas para los animales ni típicamente levantinas para las humanas. Ejemplos clásicos los encontramos dentro de la propia sierra de Albarracín -Dos Caballos, Doña Clotilde, Tío Campano, Los Callejones I-, en espacios geográficos próximos, como la serranía de Cuenca -Selva Pascuala- o en estribaciones más orientales, como la cuenca del río Martín -Los Borriquitos, Los Trepadores-.

La complejidad interpretativa de estas escenas es tal que, acerca de algunos ejemplos concretos -abrigo del Tío Campano-, se dice que su definición impide “... la interpretación de esta temática como una caza a lazo...", para decir a continuación que la actitud del animal "... contradice su domesticación...” (Piñón, 1981: 206). En cualquier caso, las dudas acerca de la interpretación de estas escenas resultan manifiestas, habiéndose tildado de "pinturas controvertidas" (Utrilla, 2000: 64), pudiéndose identificar tanto como escenas de domesticación

7 También Martínez Bea, M.: Variabilidad estilística y distribución territorial del arte rupestre levantino en Aragón. El ejemplo de La Vacada (Castellote, Teruel). Tesis doctoral inédita defendida en 2005 en la Univ. de Zaragoza. como de caza a lazo (Beltrán, 2002: 124), esta última interpretación probablemente por la consideración apriorística de que el arte levantino debería de ser un arte enteramente de cazadores.

Además de las denominadas escenas de domesticación o de captura a lazo como las aludidas, en el arte levantino la relación entre grandes figuraciones de bóvidos naturalistas y representaciones humanas se circunscribe casi en su totalidad a una temática cinegética, de componente masculino y de carácter acumulativo, resultando en todo caso una escenografía escasa en número. Entre éstos aparecerían los conjuntos de La Vacada, Cueva Remigia, abrigo viII de Mola Remigia, Cavalls o la Vieja de Alpera, todos ellos con flechas clavadas en el cuerpo y/o formando escenas acumulativas con representaciones humanas masculinas disparando o persiguiendo a los animales. También en Prado del Navazo encontramos una temática afín, en la que un grupo de arqueros disparan a una manada de grandes toros, si bien existen marcadas diferencias de actitud (los arqueros aparecen estáticos) y estilísticas, tanto para las figuras de toros como para las humanas, con respecto a los conjuntos antes mencionados.

$\mathrm{Al}$ margen de las escenas cinegéticas referidas, debemos atender a otro tipo de escenografías en las que el toro y su relación con el componente humano se han definido como "juegos de toro" (Jordá, 1976). La relación entre representaciones femeninas y bóvidos queda reflejada en ámbitos más allá de los cinegéticos, si bien de forma minoritaria, siendo el de Roca dels Moros de Cogul el más destacado. Sin embargo, la expresión acumulativa de sus figuraciones y la manifiesta falta de una actividad compartida que denote la existencia real de una escena sincrónica y en relación con las figuras animales nos impide realizar una lectura afín a la manifestada en el panel 3 del Arquero de los Callejones Cerrados.

Quizá, como paralelo temático y escénico más próximo podríamos citar el de la Peña del Escrito (Villar del Humo), conjunto para el que Jordá define una figura animal, posiblemente un ternero, que sería sujeto por una representación femenina con falda, aunque en este caso se habla de una posible ofrenda (Jordá, 1975: 8), apuntando incluso 
la posible "presencia de una sacerdotisa (?)" (Jordá, 1976: 209). Si bien el calco que se aporta en las publicaciones referidas es preliminar, lo cierto es que la interpretación ofrecida se debe apuntar, cuando menos, como dudosa. En esta línea se puede citar la revisión del conjunto en la que se elaboraron nuevos calcos, de manera que se especifica que “... junto a ella (la figuración femenina) aparece una figura animal de muy difícil identificación. El perfil de su cabeza recuerda al de una cierva, aunque dos pequeńas protuberancias en la parte superior de la misma podrían corresponder a unos pequeños cuernos al comienzo de su desarrollo..." (Ruiz, 2005: 244). El mal estado de conservación del conjunto impide realizar mayores precisiones, sin que se pueda descartar en términos absolutos la interpretación del zoomorfo como un ciervo, ternero o incluso cáprido, temática ampliamente representada en el abrigo referido.

Resulta asimismo significativa la relación espacial de los zoomorfos y de las figuras humanas del panel 3. Todas las especies animales asociadas a antropomorfos son susceptibles de ser domesticadas -bóvidos, équidos y cápridos-, mientras que la única especie animal del panel 3 que aparece aislada y con una flecha clavada es, precisamente, la única no domesticable-cérvido-.

\subsection{Aspectos técnicos}

La coloración blanquecina muy desvaída del panel 3, como ya se ha destacado, hace muy complicada la visibilidad del conjunto incluso a plena luz del día. Desde una perspectiva técnica, el uso de pigmento blanco en el abrigo del Arquero de los Callejones Cerrados no es un elemento singular en la sierra de Albarracín, ya que se encuentra bien representado en otros abrigos de Albarracín, Bezas y Tormón. Sin embargo, la importancia de su uso se manifiesta en el vínculo directo con la tradición en el empleo de esta coloración en toda la Sierra.

La tonalidad blanquecina, lechosa o pajiza como las define Beltrán (1986: 38-39), de estas manifestaciones no sólo debería explicarse como la búsqueda del contraste con la coloración rojiza del rodeno, ya que existen en abrigos de la zona -incluso en el

(C) Universidad de Salamanca que centra nuestro estudio- figuras rojas, pardas, carmín o anaranjadas cuya visibilidad no disminuye, pudiéndose apreciar perfectamente en el panel 2 del abrigo que nos ocupa. De hecho, en el 58,9\% de los conjuntos decorados se documenta un único color en la confección de sus motivos. Entre éstos es el rojo, en sus diferentes tonalidades, el más representado -con un 73,9\%-, seguido del blanco $-21,7 \%-$ y del negro $-4,4 \%-$. De la totalidad de abrigos decorados, en un 33,3\% se emplearon dos colores diferentes -rojo y blanco en un $61,5 \%$; blanco y negro en un 30,8\%; y rojo y negro en un 7,7\%-; mientras que sólo en un 7,8\% del total de abrigos se constata el uso de los tres colores: rojo, blanco y negro.

El empleo del color blanco no obedecería, por tanto, a la búsqueda de contraste con el soporte rojizo del rodeno, ni su uso es anecdótico o puntual en la Sierra de Albarracín, como ocurre en otros casos, limitado a la realización de detalles o adornos de figuras rojas previas, como ya hayan apuntado diferentes autores para otros conjuntos como Marmalo IV, Civil o Centelles (Cabré, 1925: 215-219; Domingo, 2006: 160-161 y 187; Villaverde et al., 2006: 193; López, 2007: 131; Hernanz et al., 2012: 357).

Acerca del componente cromático no consideramos que éste pueda ser considerado como un marcador cronológico, siquiera relativo, al menos para la Sierra de Albarracín, de manera que se debe “... relativizar la unívoca consideración metodológica del color como elemento-guía para el establecimiento de sistemas evolutivos..." (Piñón, 1981: 425). En efecto, las ordenaciones cronológicas atendiendo a la coloración de las representaciones no resultan válidas, toda vez que no parece posible una clasificación cronológica lineal, sino que ésta se presenta mucho más compleja, apuntando a una posible coexistencia o alternancia indistinta en el empleo de los diferentes colores.

Asimismo, la técnica -tinta plana- y la tonalidad empleadas propician una gran homogeneidad para todas las figuraciones, hasta el punto de que es imposible tratar de establecer un secuencia de ejecución para la totalidad de los motivos a partir de superposiciones. Esta problemática se ve agudizada 
por la complejidad interpretativa de la propia escena, su concentración en un espacio muy reducido con un número relativamente bajo de figuraciones humanas y especies animales diferentes y que no parecen desarrollar una única escena conjunta.

A pesar de ello, atendiendo a la lectura y análisis compositivo de la escena, hemos establecido una secuencia de ejecución, siquiera parcial, centrada en los motivos 6-7 y 8-9. Así, las dos representaciones de grandes bóvidos -motivos 6-7-, como se ha apuntado, protagonizarían una escena de acoplamiento, en la que el gran toro macho apoyaría sus patas delanteras sobre la cruz de la hembra durante la monta. En sí misma se trataría de una escena bien delimitada, pero su lectura se hace más compleja cuando en ésta intervienen las dos representaciones femeninas del conjunto. En especial una de ellas -motivo 5-, que estira un brazo que contacta con la cabeza del bóvido hembra (Fig. 6).

Resulta imposible tratar de dar un sentido único y pleno a la acción que tanto podría representar una escena acumulativa en la que la adición de la humana añadiría un significado distinto a la escena original -acoplamiento de bóvidos-, o bien que se tratara de una escena única, bien determinada y sincrónica en su ejecución con la participación directa de los componentes referidos. La exacta tonalidad empleada en la confección de todas estas figuraciones hace que nos planteemos la sincronicidad de su realización.

Con todo, y en cualquiera de los dos casos, el sentido simbólico de la acción resulta imposible de aprehender, pudiéndose tratar de una escena de fertilidad en la que la mujer se imbuiría de la misma tocando al bóvido hembra en el curso de la monta; tratarse de una escena de domesticación -con las implicaciones cronoculturales que conllevaría esta opción para el arte levantino-, o bien contar con algún valor ritual, simbólico o religioso cuyo significado se nos escapa.

En cualquier caso, la importancia radica precisamente en la participación en una escena cargada de simbolismo de figuras humanas de aspecto levantino y no de estilizaciones susceptibles de clasificarse como esquemáticas.

(C) Universidad de Salamanca
Mayores dificultades, en cuanto a la hermenéutica, presenta otra posible escena en la que nuevamente un antropomorfo, en esta ocasión masculino -motivo 10-, aparece en contacto con un animal, cogiendo bien la pata trasera del cáprido - motivo 8-, bien la cabeza de un bóvido -motivo 11-. El peor estado de conservación de estas figuraciones, unido a la acumulación -yuxtaposición y superposiciones- de otras representaciones, dificulta en gran medida la correcta lectura de la escena. Con todo, es posible identificar nuevamente una figura humana en actitud estática -se muestra sentada- que mediante un objeto alargado, lineal y fino -quizá algún tipo de cuerda, honda o vara?- contacta con un zoomorfos.

Sin poder realizar afirmaciones categóricas, consideramos que este antropomorfo podría estar cogiendo la pata trasera del cáprido, formando una escena de captura del animal junto al otro antropomorfo -motivo 9-. Esta temática, si bien no es habitual, cuenta con paralelos en otros conjuntos levantinos, aunque en estos casos el animal apresado es el ciervo: Muriecho, Los Chaparros (Utrilla y Martínez Bea, 2005).

Como se ha destacado, el motivo 9 -posible arquero- formaría parte de la escena de apresamiento del cáprido. No obstante, en este caso, y a pesar de que su lectura resulta más clara que en el caso anterior, se trata de una interpretación compleja al poder contar con diferentes interpretaciones según se defina como acumulativa o no. Según nuestra opinión, la figura humana podría corresponderse en realidad con la de un arquero, con una disposición similar a la vista para el motivo 2 del mismo abrigo. Sin embargo, la plasmación posterior y superpuesta

8 Otros conjuntos de la Sierra de Albarracín presentan figuraciones que portan objetos de aspecto lineal más o menos rectilíneos o curvilíneos que se han interpretado como varas o incluso látigos (Piñón, 1982: 179), aunque nos parece más factible su identificación como cuerdas o lazos. Es el caso de motivos levantinos, como el del Prado de las Olivanas; o de otros de tendencia más estilizada o esquematizante, como los de Dos Caballos o Dońa Clotilde. En otros contextos geográficos se documentan objetos de morfología similar que se han identificado como bumeranes o armas arrojadizas (Picazo y Martínez Bea, 2005). 
1

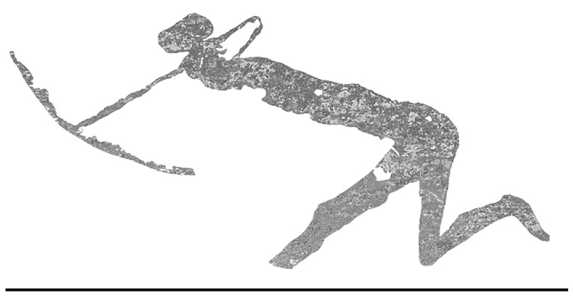

2

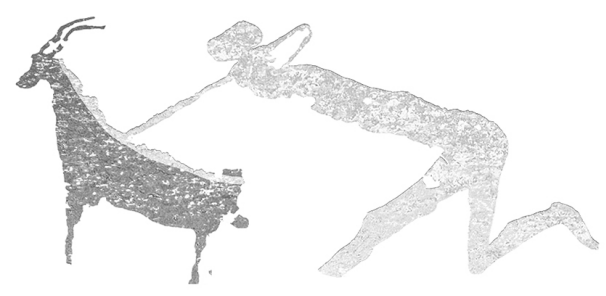

3

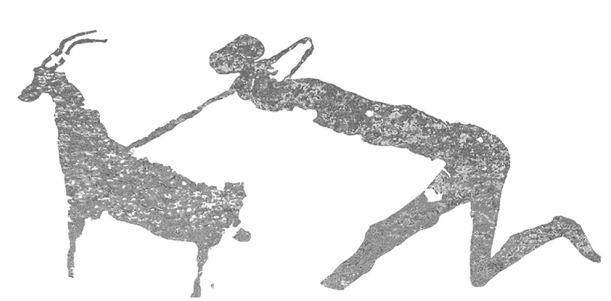

FIG. 10. Secuencia de confección propuesta para la escena entre humano y cáprido del panel 3: 1) arquero, en disposición y actitud similar a la observada para el motivo 2 del panel 2; 2) realización posterior del cáprido aprovechando la curvatura del arco como lomo del animal; 3) aspecto final de la composición.

de la representación de cáprido habría tapado el arco -siendo aprovechado como curvatura del lomo del animal-, de manera que una figura previa de arquero se habría transformado en una escena de captura del animal directamente con la mano (Fig. 10).

\section{Conclusiones}

También en el abrigo que nos ocupa, es la figura humana la que dota de mayor singularidad a un conjunto rupestre postpaleolítico de tendencia naturalista. El abrigo del Arquero de los Callejones Cerrados no es el único conjunto de la Sierra de Albarracín con figuraciones animales y humanas de color blanco que comparten espacio, esta circunstancia se documenta también en el del Prado del Navazo, y quizá en el abrigo de Prado Medias, aunque en este caso los restos de color blanco aparecerían muy mal conservados (Bea, 2012). Sin embargo, en el Prado del Navazo las representaciones humanas, muy estilizadas y de dimensiones muy pequeñas en comparación a las grandes figuras de toros, parecen responder más a una verdadera acumulación figurativa.

Desde el punto de vista de la temática, destaca la representatividad de las especies animales que, a pesar de su reducido número, plasman la totalidad de las que se presentan en los conjuntos de la Sierra de Albarracín. Además, en el panel 3 del conjunto que nos ocupa, aparecen agrupadas y en relación con motivos humanos aquellas especies susceptibles de ser domesticables, mientras que el cérvido (la única salvaje) se representó separada y con una flecha clavada, subrayando su relación con el mundo cinegético.

De entre las especies animales documentadas en el abrigo, es el bóvido el zoomorfo más destacado del conjunto, tanto por su número como por su directa interacción con figuraciones humanas. Desde un punto de vista global, el bóvido es el animal más importante de los representados en la Sierra de Albarracín. Al margen de las figuraciones de 'indeterminados' - una parte importante de las cuales podrían haber sido igualmente bóvidos-, el grupo más representado es el de bóvidos -35,7\%-, seguido de lejos por los cérvidos - $12,8 \%$-, cápridos -12,2\%- y équidos -9,5\%-.

La importancia simbólica del toro resulta meridiana en todo el Mediterráneo. Aparece a lo largo de la Prehistoria y en momentos plenamente históricos como un animal poderoso, asociado a la procreación y fecundidad (Álvarez de Miranda, 1962: 89; Jordá, 1975: 7), especialmente en tierras circunmediterráneas (Delgado, 1996 y 2007; Athanassopolou et al., 2002), hasta el punto de que algunos autores lo han definido como "el alpha de la Naturaleza” (Bachhofen, 1987). En esta línea, la escena referida trasciende su lectura como mero signo para definirse como un claro símbolo, preńado de significado. El que sean representaciones femeninas las que centran la acción podría incluso 


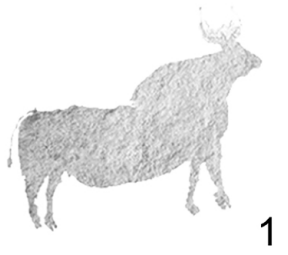

1

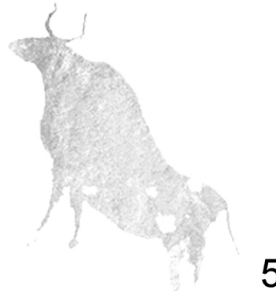

5

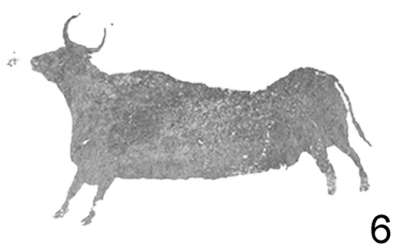

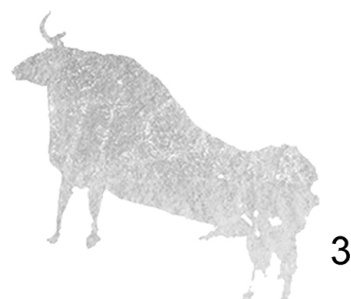

3

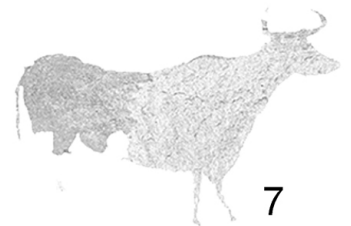

4
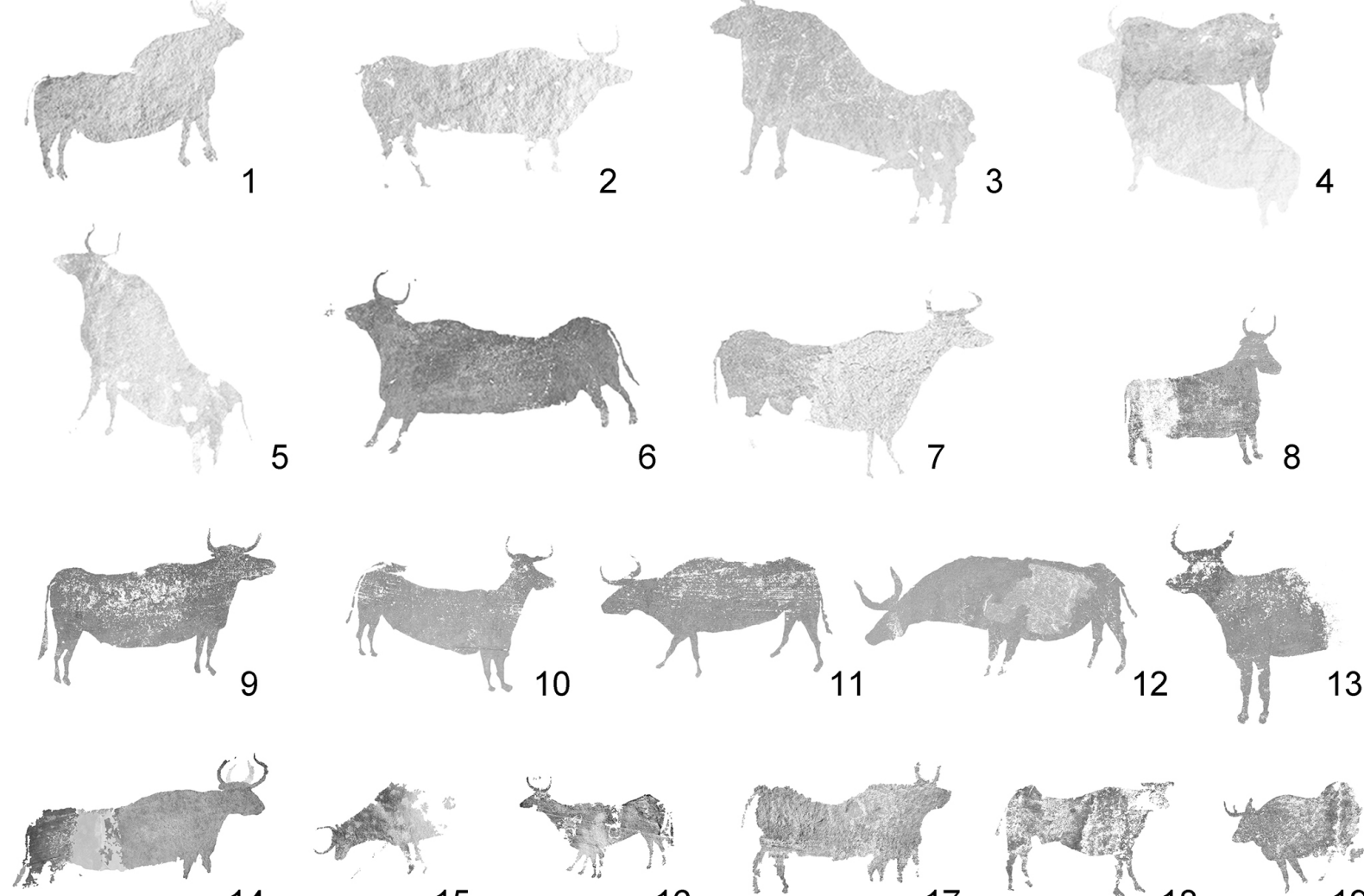

14
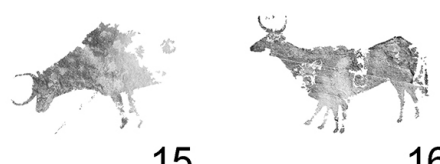

15

16
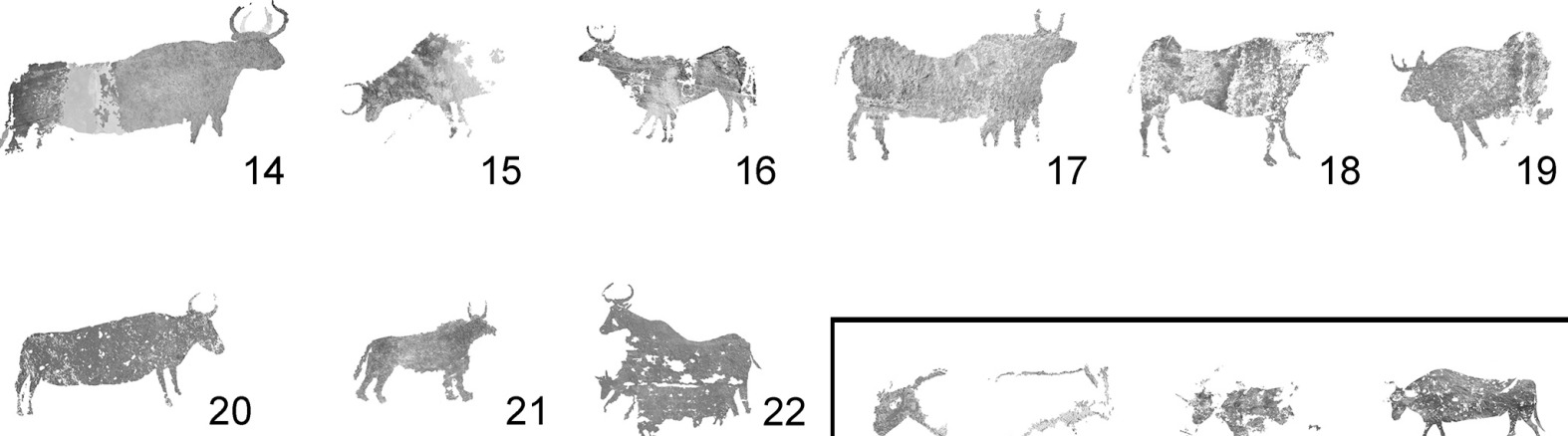

21

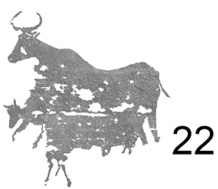

0
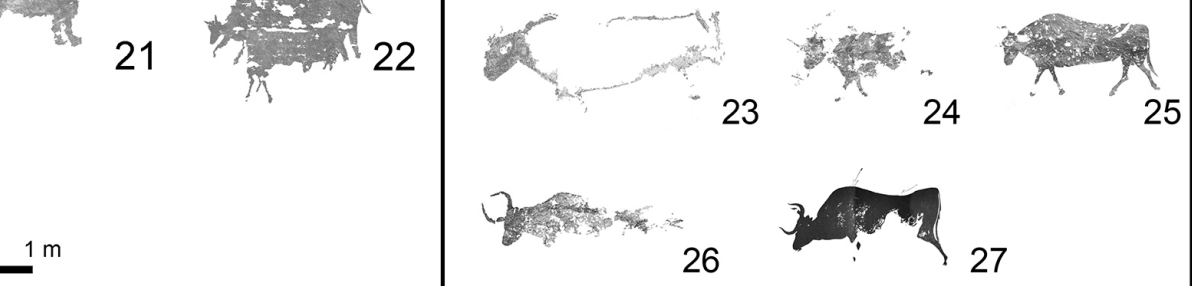

27

FIG. 11. Representaciones de bóvidos de la Sierra de Albarracín. En el recuadro una selección de grandes bóvidos del Bajo Aragón y Maestrazgo: 1-7) Cocinilla del Obispo; 8-13) Prado del Navazo; 14) Ceja de Piezarrodilla; 15) Cerrada del Tío Jorge; 16-17) Prado de las Olivanas; 18-19) Medio Caballo; 20) Hoya de Navarejos III; 21) Hoya de Navarejos V; 22) Arquero de los Callejones Cerrados; 23) Val del Charco del Agua Amarga; 24) La Vacada; 25) El Torico; 26) Cantalar I; 27) Cingle de Mola Remigia IV (según Ripoll, 1968).

sugerir una lectura que, en la línea de lo apuntado por Bachofen, interpretara la acción como la monta de un toro por parte de la hembra -Gran Madrey sus sacerdotisas que, según sus postulados, sería algo propio de una sociedad de régimen matriarcal, típica del mundo mediterráneo y preindoeuropeo.

Pero al margen de lecturas en clave social y simbólica como las apuntadas, y sin poder entrar en 
valoraciones de atribución socioeconómica, debemos subrayar las marcadas diferencias tipológicas, de dimensiones y de colores observadas entre las figuraciones de bóvidos de la sierra de Albarracín y aquellas propias de zonas geográficas más orientales, como del Bajo Aragón y Maestrazgo turolense y castellonense (Fig. 11). Discrepancias que pueden, asimismo, abundar en la existencia de tradiciones artísticas diferenciadas con influencias culturales y atribuciones cronológicas igualmente diversas, apuntando la existencia de patrimonios simbólicos bien establecidos, tradiciones iconográficas y, posiblemente, mitologías desarrolladas regionalmente, en la línea de lo apuntado por Bandi (1988: 137) para el arte mueble paleolítico.

El abrigo del Arquero de los Callejones Cerrados, especialmente su panel 3, se presenta como uno de los más destacados del conjunto levantino en Aragón por la calidad de su ejecución, variedad temática, color empleado y simbolismo de las escenas. Pero al margen de las aportaciones que el abrigo hace al arte levantino en general, y al aragonés en particular, el presente estudio nos suscita la necesidad, cada vez más evidente e imperiosa, de redefinir cuestiones terminológicas dentro del estudio del arte rupestre postpaleolítico, especialmente del levantino. El conjunto que presentamos, con motivos animales muy naturalistas y figuraciones humanas de aspecto típicamente levantino conformando una escena conjunta, subraya la gran complejidad en la definición del propio arte levantino, de su pretendida unidad evolutiva lineal y del componente cronocultural atribuido. Consideramos que se debería contemplar una nueva clasificación, con un mayor peso de aspectos relacionados con 'ciclos' y no sólo con valores estilísticos que, a buen seguro, han llevado a que el arte levantino pueda definirse como un cajón de sastre. Los conjuntos rupestres de la Sierra de Albarracín aportarán aspectos interesantes al debate.

\section{Bibliografía}

Álvarez de Miranda, A. (1962): Ritos y juegos del toro. Madrid: Taurus.

(c) Universidad de Salamanca
Athanassopolou, S.; Azara, P. y Nicolau, A. (dirs.) (2002): Toros. Imagen y culto en el Mediterráneo Antiguo. Barcelona.

Aurell, M.; Bádenas, B. y Meléndez, A. (2010): "Geología de la Sierra de Albarracín". En Peña, J. L.; SÁnchez, M. y Lozano, M. V. (coords.): Las formas de relieve de la Sierra de Albarracín. Colección Estudios, 7. Teruel: Centro de Estudio de la Comunidad de Albarracín, pp. 13-38.

BACHOFEN, J. J. (1987): El matriarcado: una investigación sobre la ginecocracia en el mundo antiguo según su naturaleza religiosa y jurídica. Madrid: Akal.

Balbín, R.; Bueno, P.; Jiménez, P.; Alcolea, J.; FernÁndez, J. A.; Pino, E. y Redondo, J. C. (1989): "El yacimiento de Rillo de Gallo (Guadalajara)", Wad-al-Hayara, 16, pp. 31-73.

BANDI, H. G. (1988): "Mise bas et non défécation. Nouvelle interprétation de trois propulseurs magdaléniens sur des bases zoologiques, éthologiques et symboliques", Espacio, Tiempo y Forma, Serie I, t. 1, pp. 133-147.

BeA, M. (2014): "Novedades en torno al núcleo de arte levantino de la Sierra de Albarracín. El abrigo de Prao Medias (Tormón, Teruel)", Saguntum, 46, pp. 203-207.

BEA, M. y AngÁs, J. (2015): "El arte rupestre de los núcleos de Bezas y Tormón”. En BEA, M. y Angás, J. (coords.): Las pinturas rupestres de Bezas y Tormón (Teruel). Teruel: Parque Cultural de Albarracín y Dirección General de Bellas Artes y Bienes Culturales y de Archivos y Bibliotecas, pp. 50-135.

Beltrán, A. (1986): El arte rupestre en la provincia de Teruel. Cartillas Turolenses, 5. Teruel: Instituto de Estudios Turolenses.

Beltrán, A. (1993): Arte prehistórico en Aragón. Zaragoza: Ibercaja.

Beltrán, A. (1995): "Sobre el arte levantino, especialmente de Albarracín. Ideas generales para un debate". En Actas XXI Congreso Nacional de Arqueología (1991, Teruel). Zaragoza, pp. 289-315.

Beltrán, A. (1997): "Las pinturas prehistóricas de la Paridera de Tormón”. En Arqueología Aragonesa 1994. Zaragoza, pp. 45-49.

CABRÉ, J. (1925): "Las pinturas rupestres de la Valltorta. Escena bélica de la Cova del Civil", Actas y Memorias de la Sociedad Española de Antropología, Etnología y Prehistoria, III-IV, pp. 201-233.

Collado, O. (1992a): Los abrigos pintados del Prado del Navazo y zona del Arrastradero (pinturas rupestres de Albarracín). Zaragoza: Gob. de Aragón. 
Collado, O. (1992b): Parque Cultural de Albarracin. Zaragoza: Gob. de Aragón.

Cruz Berrocal, M. (2004): "La investigación del arte rupestre desde la Geografía: la pintura neolítica del ámbito mediterráneo de la Península Ibérica", Trabajos de Prehistoria, 61 (2), pp. 41-62.

Cruz Berrocal, M. (2005): Paisaje y arte rupestre: patrones de localización de la pintura levantina. BAR Int. Ser., 1409. Oxford: Archaeopress.

Delgado, C. (1996): El toro en el Mediterráneo. Análisis de su presencia y significado en las grandes culturas del mundo antiguo. Madrid: UAM.

Delgado, C. (2007): Juegos taurinos en los albores de la Historia. Madrid: Egartorre.

Domingo, I. (2006): Técnica y ejecución de la figura en el arte rupestre levantino. Hacia una definición actualizada del concepto de estilo: validez y limitaciones. Valencia: Univ. de Valencia.

Domingo, I.; López, E.; Villaverde, V.; Guillem, P. y Martínez-Valle, R. (2003): "Las pinturas rupestres del Cingle del Mas d'en Josep (Tírig, Castelló). Consideraciones sobre la territorialización del arte levantino a partir del análisis de las figuras de bóvidos y jabalíes", Saguntum, 35, pp. 9-49.

Hernanz, A.; Ruiz, J. F. y Gavira, J. (2012): "Pigmentos, aglutinantes y pátinas: caracterización fisicoquímica de la tecnología de las pinturas rupestres levantinas". En García, J. J.; Collado, H. y Nash, G. (eds.): El problema levantino. Cáceres-Budapest: Archaeolingua, pp. 345-365.

Herrero, M. A.; Nieto, E.; Collado, O.; Martínez, M. R. y Loscos, R. M. (1994): "Informe sobre la campaña de documentación del arte rupestre del conjunto de Albarracín (Albarracín, Teruel”. En Arqueología Aragonesa 1991. Zaragoza, pp. 25-30.

JordÁ, F. (1975): "La Peña del Escrito (Villar del Humo, Cuenca) y el culto al toro", Cuadernos de Prehistoria y Arqueologia Castellonense, 2, pp. 7-9.

JordÁ, F. (1976): "¿Restos del culto al toro en el Arte Levantino?”, Zephyrus, xxvi-XxvII, pp. 187-216.

López Montalvo, E. (2007): Análisis interno del arte levantino: la composición y el espacio a partir de la sistematización del núcleo Valltorta-Gasulla. Valencia: Univ. de Valencia.

Martínez Bea, M. (2008): "Arte rupestre de Albarracín: la excepcionalidad de un conjunto interior". En Hernández, M. S. y Soler, J. A. (eds.): Actas del Congreso de Arte Rupestre en la España Mediterránea. Alicante: MARQ, pp. 141-148.

Martínez Utrillas, L. (coord.) (2012): El Parque Cultural de Albarracin: arte rupestre Patrimonio Mundial. Teruel.
Nieto, E.; Herrero, M. A. y Collado, O. (1994): "Memoria sobre la actuación en el Parque Cultural de Albarracín durante 1991". En Arqueología Aragonesa 1991. Zaragoza, pp. 31-34.

Picazo, J. y Martínez Bea, M. (2005): "Bumeranes y armas arrojadizas en el arte levantino. Las aportaciones de la Cueva del Chopo (Obón, Teruel)”. En Hernández, M. S. y Soler, J. A. (eds.): Actas del Congreso de Arte Rupestre en la España Mediterránea. Alicante: MARQ, pp. 379-391.

Piñón, F. (1982): Las pinturas rupestres de Albarracín (Teruel). Monografías del Centro de Investigación y Museo de Altamira, 6. Santander.

Porcar, J. (1947): "Iconografía rupestre de Gasulla y Valltorta. Representación pictográfica del toro”, Boletin de la Sociedad Castellonense de Cultura, XxiII, pp. 314-324.

Ripoll, E. (1968): The painted shelters of La Gasulla (Castellón). Monographs on the Cave Art, Levantine Art, 2. Barcelona.

Rubio, M (1995): "Aproximación al estudio de las figuras zoomorfas representadas en el Arte $\mathrm{Ru}-$ pestre Levantino", Recerques del Museu d'Alcoi, 4, pp. 103-109.

Ruiz, J. F. (2005): "Peña del Escrito II (Villar del Humo, Cuenca). Revisión de un abrigo clásico". En HernÁndez, M. S. y Soler, J. A. (eds.): Actas del Congreso de Arte Rupestre en la España Mediterránea. Alicante: MARQ, pp. 235-250.

Ruiz, J. F. (2009): "Los Arenales. Una nueva estación con arte rupestre en Villar del Humo, Cuenca", Zephyrus, LXIII, pp. 207-224.

Utrilla, P. (2000): El arte rupestre en Aragón. Colección CAI 100, n. ${ }^{\circ} 56$. Zaragoza.

Utrilla, P. (2005): "El arte rupestre en Aragón. 100 años después de Calapatá”. En Hernández, M. S. y Soler, J. A. (eds.): Actas del Congreso de Arte Rupestre en la España Mediterránea. Alicante: MARQ, pp. 341-377.

Utrilla, P. y Martínez Bea, M. (2005): "La captura del ciervo vivo en el arte prehistórico", Munibe, 57 (3), pp. 161-178.

Villaverde, V.; Guillem, P. y Martínez-Valle, R. (2006): "El Horizonte gráfico Centelles y su posición en la secuencia del Arte Levantino del Maestrazgo", Zephyrus, LIX, pp. 181-198.

VIŃAS, R. y SARRIÁ, E. (1978): "Las representaciones faunísticas del término de Ares del Maestre (Castellón de la Plana)", Cuadernos de Prehistoria y Arqueología Castellonense, 5, pp. 143-161. 